\title{
A Randomized Controlled Trial of a Citywide Emergency Department Care Coordination Program to Reduce Prescription Opioid Related Visits: An Economic Evaluation
}

\author{
Sean M. Murphy, PhD, \\ Department of Health Policy and Administration, Washington State University College of Nursing, \\ PO Box 1495, Spokane, WA 99210-1495, USA. Program of Excellence in Addictions Research, \\ Washington State University College of Nursing, PO Box 1495, Spokane, WA 99210-1495, USA \\ Donelle Howell, PhD, \\ Program of Excellence in Addictions Research, Washington State University College of Nursing, \\ PO Box 1495, Spokane, WA 99210-1495, USA \\ Sterling McPherson, PhD, \\ Program of Excellence in Addictions Research, Washington State University College of Nursing, \\ PO Box 1495, Spokane, WA 99210-1495, USA \\ Rebecca Grohs, RN, BSN, CCM, \\ Program of Excellence in Addictions Research, Washington State University College of Nursing, \\ PO Box 1495, Spokane, WA 99210-1495, USA \\ Jon Roll, PhD, and \\ Program of Excellence in Addictions Research, Washington State University College of Nursing, \\ PO Box 1495, Spokane, WA 99210-1495, USA

\section{Darin Neven, MS, MD} \\ Program of Excellence in Addictions Research, Washington State University College of Nursing, \\ PO Box 1495, Spokane, WA 99210-1495, USA
}

\section{Abstract}

\begin{abstract}
Background-Care provided in the emergency department (ED) can cost up to 5 times as much as care received for comparable diagnoses in alternative settings. Small groups of patients, many of whom suffer from an opioid use disorder, often account for a large proportion of total ED visits. We recently conducted, and demonstrated the effectiveness of, the first randomized controlled trial of a citywide ED care-coordination program intending to reduce prescription-opioid-related ED visits. All EDs in the metropolitan study area were connected to a web-based information exchange system.
\end{abstract}

Objective-The objective of this paper was to perform an economic evaluation of the 12-month trial from a third-party-payer perspective. 
Methods-We modeled the person period monthly for the 12-month observation period, and estimated total treatment costs and return on investment (ROI) with regard to cost offsets, over time, for all visits where the patient was admitted to, and discharged from the ED.

Results-By the end of month 4 the mean cumulative cost differential was significantly lower for intervention relative to TAU participants $(-\$ 1,370 ; \mathrm{p}=0.03)$; this figure climbed to $-\$ 3,200$ $(\mathrm{p}=0.02)$ by the end of month 12 . The ROI trended upward throughout the observation period, but failed to reach statistical significance by the end of month $12(\mathrm{ROI}=3.39, \mathrm{p}=0.07)$.

Conclusion-The intervention produced significant cost offsets by the end of month 4, which continued to accumulate throughout the trial; however, ROI was not significant. Since the perpatient administrative costs of the program are incurred at the time of enrollment, our results highlight the importance of future studies that are able to follow participants for a period beyond 12 months in order to more accurately estimate the program's ROI.

\section{Keywords}

Economic evaluation; Frequent ED Use; ED care coordination; Nonmedical prescription opioid use

\section{INTRODUCTION}

The Patient Protection and Affordable Care Act (ACA), focuses on achieving the objectives of the Triple Aim ${ }^{\circledR}$; they are: improve the quality of patient care, improve population health and reduce the cost of per-capita healthcare. ${ }^{1}$ Among the financial incentives for providers and insurers to achieve these objectives under the ACA, particular emphasis has been placed on care coordination; however, this process often breaks down when patients seek care at the emergency department (ED). For example, Stiell et al. ${ }^{2}$ found that ED providers did not have relevant patient information such as medical history and laboratory test results, in almost one-third of the ED visits they examined. This information was deemed to be crucial to patient care in just under half of the cases examined. Moreover, the lack of information resulted in an average ED length-of-stay increase of 1.2 hours.

The ED is generally believed to be an area capable of large efficiency gains for the healthcare system. Many ED visits are thought to be non-emergent, and therefore treatable in an alternative setting ${ }^{3,4}$; what's more, recent statistics show that over $60 \%$ of ED visits occur during business hours. ${ }^{5}$ Patient care provided in the ED is expensive relative to care received in alternative settings, with findings indicating ED care may cost up to 5 times as much for comparable diagnoses. ${ }^{6-8}$ Additionally, it has been shown that small groups of patients often account for a relatively large proportion of total ED visits. LaCalle and Rabin's ${ }^{9}$ systematic literature review revealed that between $4.5 \%$ and $8 \%$ of ED users account for $21 \%$ to $28 \%$ of all ED visits. Frequent ED users are generally in relatively poor physical health, ${ }^{10}$ and suffer from comorbid substance-use or mental-health disorders. ${ }^{10-16}$

Consequently, this population consumes immense quantities of healthcare resources. ${ }^{14,17-20}$ Furthermore, heavy ED use has been associated with ED crowding, which can culminate in longer wait times, undue stress on ED staff and even inferior treatment outcomes. ${ }^{18,21-28}$ These findings imply that a targeted multidisciplinary ED care-coordination program could 
be very beneficial to this patient population, providers, hospitals/health systems, payers and society as a whole.

We recently completed, and demonstrated the effectiveness of, a multisite, randomized controlled trial of a citywide ED care-coordination program with a web-based information exchange system, for the management of frequent ED users exhibiting opioid-prescriptionseeking behavior. ${ }^{29}$ Participants in the care-coordination intervention had fewer visits to the $\mathrm{ED}$, received fewer opioids and opioid prescriptions in the ED, and had fewer prescribers over the 12-month observation period. However, evidence of effectiveness is often not sufficient for implementation of such programs, given the resource constraints faced by payers of healthcare services. Therefore, the average cost of $\$ 729$ per patient for this intervention (see the Cost Measures section below) may serve as a barrier to adoption if potential downstreatm cost-offsets are not taken into account. The objective of this study was to conduct a longitudinal economic analysis of the ED care-coordination program from a third-party-payer perspective. The findings from this study will be an important contribution to the literature given the unique nature of our program and the very limited number of studies that have evaluated the cost of other multidisciplinary case-management interventions for frequent ED users, ${ }^{30}$ as well as the weaknesses associated with the design and analyses of those prior studies.

\section{METHODS}

\section{The Multidisciplinary ED Care-Coordination Trial}

A 12-month randomized controlled trial designed to test the effectiveness of a multidisciplinary ED care-coordination program with regard to ED visits, amount of opioids prescribed and the number of opioid-analgesic prescriptions written in the ED was conducted between March 2012 and July 2013, with study enrollment ending in July 2012. ${ }^{29}$ The program is designed to reduce "unnecessary" use of the ED, while also ensuring that patients get the care they need in the appropriate setting. An individualized ED care plan is created for each participant by a team of healthcare providers, including the patient's primary care physician, ED physicians and nurses, and mental health and substance-usedisorder professionals, among others. Additionally, the program is connected to a web-based information exchange system capable of sharing relevant patient information with ED care providers and other stakeholders, such as case managers and primary care providers, in realtime, whenever an enrolled patient registers at an ED using the system. The framework and day-to-day administration of the program have been described in detail elsewhere. ${ }^{29,31}$

Patients in the control group received treatment as usual (TAU) in the ED. Data on ED use and costs, as well as prescriptions written were collected on participants for the 365 days prior to and following randomization. The study was approved by the Washington State University Institutional Review Board, and each of the study hospitals. A waiver of informed consent was obtained to ensure that being part of the study did not influence participant behavior or affect the patient-physician relationship.

The study took place in a metropolitan area in Washington State with a population of just over 250,000 people. The metropolitan area contained 3 hospitals, all of whom participated 
in the study. Each hospital belonged to a separate healthcare system, and each had an ED that was connected to the web-based information exchange system described above.

Potential participants were selected in descending order of total ED visits in the 12-months prior to January 2012, across all 3 EDs in the catchment area. Eligible participants were at least 18 years of age; had 5 or more ED visits in the 12 months prior to trial enrollment, the majority of which were related to non-cancer pain complaints or drug seeking behaviors; did not already have an ED care plan in place; did not have a medical condition that could interfere with safe study participation in the trial; did not have any indication of acute suicidal behaviors in their medical record in the 30 days prior to enrollment; and did not have a high frequency of ED visits for medical reasons other than pain (e.g., serial inebriation). The final randomized sample consisted of 165 participants; 82 who were enrolled in the care-coordination program, and 83 in the control group. See Neven et al. ${ }^{29}$ for full details of the study rationale and design.

\section{Findings from the Trial ${ }^{29}$}

Relative to the control arm, those in the intervention arm experienced a $34 \%$ decrease in the incidence of ED visits (IRR $=0.66, \mathrm{p}<0.001 ; 95 \% \mathrm{CI}: 0.57-0.78$ ) and an $80 \%$ decrease in the odds of receiving an opioid prescription from the $\mathrm{ED}(\mathrm{OR}=0.21, \mathrm{p}=0.001)$. Declines of $43.7 \%, 53.1 \%, 52.9 \%$ and $53.1 \%$ were observed in the treatment group for morphine milligram equivalents, controlled substance pills, prescriptions and prescribers, respectively.

\section{Economic Evaluation}

We conducted an economic analysis alongside the trial of the multidisciplinary ED carecoordination program. The analyses were conducted from the perspective of a third-party payer. This is an appropriate perspective to adopt here, as the program can be implemented as a stand-alone program, yet it is capable of impacting patient care across multiple providers, as it did in this study. Since the intent of an economic analysis is to inform "real world" resource allocation decisions, and given the diversity that is likely to occur in health insurance type among participants, resources were conservatively valued according to the actual estimated costs of providing the measured services.

\section{Cost Measures}

The number of ED visits, and the direct and indirect treatment costs associated with each visit were obtained from the hospitals. Given that the objective of the care-coordination program is to reduce "unnecessary" ED visits associated with prescription-opioid-seeking behavior, we focused only on visits that were most likely to reflect such behavior; that is, visits where the patient was both admitted to, and discharged from the ED. All expenses (direct and indirect) for providing services to patients during these visits were taken into consideration. Direct costs are those directly associated with the services provided as part of the patient's care, while indirect costs are those associated with the operation of the facility, such as administration, facilities operations, etc. The smallest of the 3 facilities, which represented just under $17 \%$ of all ED visits, was only able to give us charges; therefore, we generated cost estimates using a facility-specific cost-to-charge ratio. All costs were adjusted 
for inflation using the appropriate regional Medical Care Consumer Price Index, ${ }^{32}$ and are presented in 2013 U.S. dollars.

The mean administration cost of the care-coordination program was calculated for the 2013 fiscal year using the Drug Abuse Treatment Cost Analysis Program (DATCAP) instrument. ${ }^{33}$ The DATCAP is designed to estimate the value of resources utilized by programs in a variety of settings. The instrument allows for the estimation of both accounting and economic costs. Accounting costs are defined as "the actual expenditures and depreciation of all resources used by the treatment program." ${ }^{34}$ Economic costs are considered to be accounting costs, as well as the value of any resources used by the program that are either subsidized or used free of charge. The monthly accounting cost of administering and managing the program was estimated to be $\$ 19,376$. This figure does not, however, include the value of the time donated by the multidisciplinary guidelines committee, which was valued at $\$ 936$ per month, nor does it include the monthly cost of the information exchange system, which for the 3 hospitals in our study came to $\$ 3,754$ per month. Adding these figures to the accounting cost brings the monthly economic cost of the program to $\$ 24,066$. The resources described above allow the program to enroll 33 participants per month, on average. Therefore, since that the vast majority of program costs are incurred at enrollment, the one-time per-patient program cost is estimated to be approximately $\$ 729$.

\section{Return on investment (ROI) measurement}

ROI is a measure of the net benefit associated with an investment, relative to the cost of the investment. Thus, the numerator in our ROI ratio is calculated as the mean total cost differential between the intervention and control arms, minus the mean cost of the carecoordination program, while the denominator is the mean cost of the care-coordination program.

\section{Analysis}

Differences in patient characteristics were tested via chi-square tests for categorical variables and $\mathrm{t}$-tests for continuous variables. We modeled the person period monthly for the 12month observation period. All analyses were intention-to-treat.

A multivariable generalized linear model (GLM), with standard errors clustered by participant, was used to predict total treatment costs. The modified Parks test was used as a guide to choosing the appropriate variance structure for the GLM, and the Pearson Correlation, Pregibon Link and Modified Hosmer and Lemeshow tests assisted in choosing the proper mean function. ${ }^{35}$ The method of recycled predictions was used to generate the predicted mean costs for each arm, by month. ${ }^{35}$ The intervention's ROI was then calculated for each month using the predicted cumulative cost differential and the mean cost of the program.

Missing data was not an issue due to the information being obtained from hospital administrative records. To account for sampling uncertainty standard errors, $p$-values and confidence intervals were estimated within the multivariable framework via a nonparametric 
bootstrap. As a sensitivity analysis, we varied the per-patient cost of the program. All analyses were conducted using Stata 14.0.

\section{RESULTS}

We evaluated 163 of the 165 participants in the randomized intent-to-treat sample. Two participants were randomized to TAU, but were found to be suicidal prior to the establishment of an official enrollment date; therefore, we were unable to create the uniform 12-month observation period for them. The descriptive statistics for the intervention $(n=82)$ and control $(\mathrm{n}=81)$ arms are displayed in Table 1 . Patients did not differ significantly according to age, gender, race, primary form of insurance, or total visits or treatment costs for the 12 months prior to the start of the trial.

Table 2 contains the predicted mean treatment costs for each arm, by month, as well as the cumulative cost differential and ROI. Additionally, the cost figures for each study arm, and the cumulative cost differential can be viewed graphically over time in Figure 1, while Figure 2 graphically displays the ROI over time. The cumulative cost differential between the intervention and TAU arms became statistically significant by the end of Month 4 $(\$-1,370, \mathrm{SE}=626 ; \mathrm{p}=0.03)$. Total treatment costs over the entire 12-month observation period were $\$ 5,785$ and $\$ 8,985$ for the intervention and TAU arms, respectively, resulting in a cumulative cost differential of $-\$ 3,200(\mathrm{SE}=1,345 ; \mathrm{p}=0.02)$. Although the ROI trended upward throughout the observation period, it failed to reach statistical significance at the traditional $5 \%$ level by the end of the 12 months ( $3.39, \mathrm{SE}=1.85 ; \mathrm{p}=0.07)$. Our sensitivity analyses indicate that a $20 \%$ reduction in the per-patient cost of the intervention to $\$ 583$ (which is the approximate accounting cost of the intervention - see the Cost Measures section above) would be required for the ROI to reach statistical significance at the 5\% level by the end of month 12 . At this point, the ROI would be 4.49 ( $\mathrm{SE}=2.31 ; \mathrm{p}=0.05$ ), indicating that for every dollar spent on the intervention the payer would see $\$ 4.49$ worth of net benefits in the way of cost-offsets in the ED, assuming the program could maintain its effectiveness.

\section{DISCUSSION}

By the end of month 4 of the ED care-coordination program the cumulative cost differential for the intervention arm relative to the TAU arm was $-\$ 1,370(\mathrm{P}=0.03)$; the cost differential continued to rise through the end of the observation period (Figure 1), reaching $-\$ 3,200$ $(\mathrm{p}=0.02)$ by the end of month 12 . The payer's ROI associated with the program also climbed throughout the observation period reaching 3.39 by the end of month 12 (Figure 2); however, it failed to reach statistical significance at the $5 \%$ level. Given that the $5 \%$ level of significance, although conventional, is largely arbitrary, we feel it is worth noting that the ROI did reach statistical significance at the 7\% level. That is, our results indicate that 93 times out of 100 the payer could expect to see a net benefit of \$3.39 in the ED for every \$1 invested in the intervention, by 12 months. Moreover, it appears that the cost-offsets and ROI would continue to climb after 12 months; however, we are unable to confirm this without a longer follow-up period. Furthermore, separate analyses of the parent ED carecoordination program indicated that economies-of-scale opportunities may exist, implying 
that the fixed per-patient program cost of $\$ 729$ would decrease as the program expanded in terms of both patients and resources. The decrease in the per-patient cost of the program would increase the ROI, assuming the effectiveness of the program could be sustained. Our sensitivity analyses indicate that if the payer could reduce the cost $20 \%$ to $\$ 583$ per patient, they would see a significant ROI of 4.49 by the end of month 12 .

Although other cost analyses of ED care-coordination programs have been conducted, ${ }^{30}$ including one by the authors, ${ }^{31}$ to the best of our knowledge this is only the second to be performed on a randomized controlled trial (RCT). This is an important distinction, as nonRCT studies may well suffer from regression towards the mean. ${ }^{36}$ In the other RCT, Shumway et al. ${ }^{37}$ found the hospital's costs to be similar between the intervention and control arms once the cost of the intervention was taken into account. However, this study took place in a single ED in a large metropolitan area and analzyed costs from the hospital's perspective without accounting for participants' use of the other EDs in the area. This is an important consideration given that frequent ED users often visit multiple EDs. ${ }^{38-41}$

\section{Strengths and Limitations}

The research design is a major strength of this study; however, there are also a number of significant limitations. First, the results do not reflect the "true costs" of the program to a third-party payer. We were unable to follow patients over their entire continuum of care; that is, we were unable to assess whether the payer would see cost-offsets in areas other than the ED. Given the relatively high cost of an ED visit, it is likely that other offsets would be small. Also, we used a conservative estimate for the cost of care by relying on the actual cost to the provider for services rendered. Second, we had to rely on the use of the cost-to-charge ratio for one facility to estimate the cost of care provided. That said, we were able to use a facility-specific cost-to-charge ratio, and previous findings indicate that cost-to-charge ratio estimates are quite accurate on average ${ }^{42}$; moreover, this affected fewer than $17 \%$ of our total ED visits. Third, we were unable to follow patients for more than 1 year postenrollment in the program. As mentioned above, the per-patient care-coordination program costs are incurred at enrollment; therefore, following patients over a longer period of time would give a more accurate estimate of the payer's ROI, which trended upwards throughout the 12-month observation period. Fourth, with just over 80 participants in each arm, our sample size was relatively small; however, the study was adequately powered according to our a priori power calculations and the power observed in our analyses. ${ }^{43}$

An additional factor that could affect the generalizability of our findings is that during the study period the state of Washington was implementing a statewide coordinated campaign to reduce "inappropriate" ED use among Medicaid recipients. The Washington State Health Care Authority, who oversees the state's Medicaid program, proposed a policy to deny reimbursement for ED visits deemed to be "not medically necessary". ${ }^{44}$ The policy was eventually suspended by the Washington State legislature, in favor of one that allowed hospitals to implement 7 best practices for reducing "non-emergent" ED visits. ${ }^{45}$ Although the hospitals in our study were exempted from complying with the best practices for participants during the study, it is possible that the extra attention on inappropriate ED use may have affected ED care in general. Similarly, it is possible that providers who treated a 
patient in the intervention group, and therefore saw the patient's individualized ED care plan, may have subsequently treated similar, non-intervention, patients differently than they otherwise would have. However, we believe that if these political and observational factors had an effect, they would only serve to mute our findings.

\section{CONCLUSION}

We performed an economic analysis of the first multisite RCT of a multidisciplinary ED care-coordination program, where all EDs in the metropolitan study area were connected to a web-based information exchange system capable of sharing relevant patient information in real-time. Accounting only for cost-offsets associated with a reduction in ED visits where the patient was admitted to, and discharged from the ED, the program generated significantly fewer costs by the end of the fourth month, and continued to do so throughout the 12-month observation period. Although the ROI also climbed over this same period, it fell just short of reaching statistical significance at the traditional $5 \%$ level. Given that the one-time fixed cost associated with the program is incurred at time the patient is enrolled, our results highlight the importance of future studies that are able to follow patients for a period beyond 12 months.

\section{References}

1. Institute for Healthcare Improvement. IHI Triple Aim Initiative. n.d. http://www.ihi.org/

2. Stiell A, Forster AJ, Stiell IG, van Walraven C. Prevalence of information gaps in the emergency department and the effect on patient outcomes. Cmaj. 2003; 169(10):1023-1028. [PubMed: 14609971]

3. Durand AC, Gentile S, Devictor B, et al. ED patients: how nonurgent are they? Systematic review of the emergency medicine literature. Am J Emerg Med. 2011; 29(3):333-345. [PubMed: 20825838]

4. Weinick RM, Burns RM, Mehrotra A. Many emergency department visits could be managed at urgent care centers and retail clinics. Health Aff (Millwood). 2010; 29(9):1630-1636. [PubMed: 20820018]

5. National Center for Health Statistics. National Hospital Ambulatory Medical Care Survey: 2010 emergency department summary tables. 2013. http://www.cdc.gov/nchs/ahcd/web_tables.htm-2010

6. Baker LC, Baker LS. Excess cost of emergency department visits for nonurgent care. Health Aff (Millwood). 1994; 13(5):162-171. [PubMed: 7868020]

7. Kelly KA. Shifting the cost of caring for patients with nonemergency conditions from crowded emergency departments to primary care settings. J Emerg Nurs. 1994; 20(6):454-457. [PubMed: 7745893]

8. Mehrotra A, Liu H, Adams JL, et al. Comparing costs and quality of care at retail clinics with that of other medical settings for 3 common illnesses. Ann Intern Med. 2009; 151(5):321-328. [PubMed: 19721020]

9. LaCalle E, Rabin E. Frequent users of emergency departments: the myths, the data, and the policy implications. Ann Emerg Med. 2010; 56(1):42-48. [PubMed: 20346540]

10. Hunt KA, Weber EJ, Showstack JA, Colby DC, Callaham ML. Characteristics of frequent users of emergency departments. Ann Emerg Med. 2006; 48(1):1-8. [PubMed: 16781914]

11. Doupe MB, Palatnick W, Day S, et al. Frequent Users of Emergency Departments: Developing Standard Definitions and Defining Prominent Risk Factors. Ann Emerg Med. 2012; 60(1):24-32. [PubMed: 22305330]

12. Mancuso, D., Nordlund, DJ., Felver, B. Frequent emergency room visits signal substance abuse and mental illness. 2004. 
13. Mandelberg JH, Kuhn RE, Kohn MA. Epidemiologic analysis of an urban, public emergency department's frequent users. Acad Emerg Med. 2000; 7(6):637-646. [PubMed: 10905642]

14. Genell Andren K, Rosenqvist U. Heavy users of an emergency department: psychosocial and medical characteristcs, other health care contacts and the effect of a hospital social worker intervention. Social Science and Medicine. 1985; 21(7):761-770. [PubMed: 4071113]

15. Hansagi H, Allebeck P, Edhag O, Magnusson G. Frequency of emergency department attendances as a predictor of mortality: nine-year follow-up of a population-based cohort. J Public Health Med. 1990; 12(1):39-44. [PubMed: 2390308]

16. Lowe RA, Young GP, Reinke B, White JD, Auerbach PS. Indigent health care in emergency medicine: an academic perspective. Ann Emerg Med. 1991; 20(7):790-794. [PubMed: 2064102]

17. Hansagi H, Norell SE, Magnusson G. Hospital care utilization in a 17,000 population sample: 5year follow-up. Soc Sci Med. 1985; 20(5):487-492. [PubMed: 3992289]

18. Malone RE. Heavy users of emergency services: social construction of a policy problem. Soc Sci Med. 1995; 40(4):469-477. [PubMed: 7725121]

19. Zechnich AD, Hedges JR. Community-wide emergency department visits by patients suspected of drug-seeking behavior. Acad Emerg Med. 1996; 3(4):312-317. [PubMed: 8881539]

20. Hansagi H, Olsson M, Sjoberg S, Tomson Y, Goransson S. Frequent use of the hospital emergency department is indicative of high use of other health care services. Ann Emerg Med. 2001; 37(6): 561-567. [PubMed: 11385324]

21. Davis D, Barone JE, Blackwood MM. Munchausen syndrome presenting as trauma. J Trauma. 1997; 42(6):1179-1181. [PubMed: 9210565]

22. Hoot NR, Aronsky D. Systematic review of emergency department crowding: causes, effects, and solutions. Ann Emerg Med. 2008; 52(2):126-136. [PubMed: 18433933]

23. Malone RE. Almost 'like family': emergency nurses and 'frequent flyers'. J Emerg Nurs. 1996; 22(3):176-183. [PubMed: 8949217]

24. Pitts SR, Niska RW, Xu J, Burt CW. National Hospital Ambulatory Medical Care Survey: 2006 emergency department summary. Natl Health Stat Report. 2008; (7):1-38.

25. Schappert SM, Burt CW. Ambulatory care visits to physician offices, hospital outpatient departments, and emergency departments: United States, 2001-02. Vital Health Stat. 2006; 13(159):1-66.

26. Shah MN, Cushman JT, Davis CO, Bazarian JJ, Auinger P, Friedman B. The epidemiology of emergency medical services use by children: an analysis of the National Hospital Ambulatory Medical Care Survey. Prehosp Emerg Care. 2008; 12(3):269-276. [PubMed: 18584491]

27. Sun BC, Hsia RY, Weiss RE, et al. Effect of Emergency Department Crowding on Outcomes of Admitted Patients. Ann Emerg Med. 2012

28. Trzeciak S, Rivers EP. Emergency department overcrowding in the United States: an emerging threat to patient safety and public health. Emerg Med J. 2003; 20(5):402-405. [PubMed: 12954674]

29. Neven D, Paulozzi L, Howell D, et al. A randomized controlled trial of a citywide emergency department care coordination program to reduce prescription opioid related visits. Journal of Emergency Medince. 2016

30. Kumar GS, Klein R. Effectiveness of case management strategies in reducing emergency department visits in frequent user patient populations: a systematic review. J Emerg Med. 2013; 44(3):717-729. [PubMed: 23200765]

31. Murphy SM, Neven D. Cost-effective: emergency department care coordination with a regional hospital information system. J Emerg Med. 2014; 47(2):223-231. [PubMed: 24508115]

32. Bureau of Labor Statistics. [Accessed 03/28/2014] Consumer Price Index. n.d. http:// www.bls.gov/cpi/

33. Brief Drug Abuse Treatment Cost Analysis Program (Brief DATCAP): Program Version. [computer program]. University of Miami; Coral Gables, Florida: 2003.

34. French, MT. Drug Abuse Treatment Cost Anslysis Program (DATCAP): User's Manual. University of Miami; Florida: 2003. 
35. Glick, HA., Doshi, JA., Sonnad, SS., Polsky, D. Economic evaluation in clinical trials. Oxford University Press; 2014.

36. Jones HE, Spiegelhalter DJ. Accounting for regression-to-the-mean in tests for recent changes in institutional performance: analysis and power. Stat Med. 2009; 28(12):1645-1667. [PubMed: 19358144]

37. Shumway M, Boccellari A, O'Brien K, Okin RL. Cost-effectiveness of clinical case management for ED frequent users: results of a randomized trial. Am J Emerg Med. 2008; 26(2):155-164. [PubMed: 18272094]

38. Cook LJ, Knight S, Junkins EP Jr, Mann NC, Dean JM, Olson LM. Repeat patients to the emergency department in a statewide database. Acad Emerg Med. 2004; 11(3):256-263. [PubMed: 15001405]

39. Doupe, M., Kozyrskyj, A., Soodeen, RA., Derksen, S., Burchill, C., Huq, S. An initial analysis of emergency departments and urgent care in Winnipeg. Winnipeg, Manitoba: Manitoba Centre for Health Policy; 2008.

40. Fuda KK, Immekus R. Frequent users of Massachusetts emergency departments: a statewide analysis. Ann Emerg Med. 2006; 48(1):9-16. [PubMed: 16781915]

41. Ovens HJ, Chan BT. Heavy users of emergency services: a population-based review. Cmaj. 2001; 165(8):1049-1050. [PubMed: 11699700]

42. Shwartz M, Young DW, Siegrist R. The ratio of costs to charges: how good a basis for estimating costs? Inquiry. 1995; 32(4):476-481. [PubMed: 8567084]

43. Hoenig JM, Heisey DM. The abuse of power: The pervasive fallacy of power calculations for data analysis. The American Statistician. 2001; 55(1):1-6.

44. Stevenson, J., Michael, S. Emergency rooms and medical necessity: Questions and answers from the Health Care Authority on limiting payment for "not medically necessary" in the emergency room setting. Washington State Health Care Authority; 2012.

45. Lucksted A, McFarlane W, Downing D, Dixon L. Recent developments in family psychoeducation as an evidence-based practice. J Marital Fam Ther. 2012; 38(1):101-121. [PubMed: 22283383] 


\section{ARTICLE SUMMARY}

\section{Why is this topic important?}

The emergency department (ED) is an area capable of producing large efficiency gains for the healthcare system. Frequent ED users often seek care for issues that could be addressed in an alternative setting. These patients could benefit from care coordination; however, the traditional process often breaks down when patients seek care at the ED.

\section{What does this study attempt to show?}

The objective of this paper was to conduct an economic evaluation, from a third-partypayer perspective, of a multisite randomized controlled trial (RCT) testing the effectiveness of an ED care-coordination program targeting frequent ED users who have exhibited opioid-seeking behaviors. The program is noteworthy in that all EDs in the metropolitan study area were connected to a web-based information exchange system capable of sharing relevant patient information in real-time.

\section{What are the key findings}

By the end of month 4, patients in the care-coordination program had incurred significantly fewer cumulative ED treatment costs $(-\$ 1,370 ; p=0.03)$, on average. The mean cost differential continued to grow reaching $-\$ 3,200$ ( $\mathrm{p}=0.02$ ) by the end of the 12month observation period. The payer's return on investment (ROI) for the program also climbed throughout the observation period, but failed to reach statistical significance by the end of month 12 (ROI=3.39; $\mathrm{p}=0.07)$.

\section{How is patient care impacted?}

As our RCT showed, the ED care-coordination intervention was effective at reducing ED visits, opioids and opioid prescriptions in the ED, and the number of opioid prescibers over a 12-month observation period. Furthermore, the program is designed to help this medically-complex population obtain the care they need in an appropriate setting. However, the per-patient cost of such programs can serve as a barrier to implementation. The one-time fixed cost of enrolling patients in the program, combined with the upward trending cumulative cost differential and ROI observed here, highlight the importance of observing patients for a period beyond 12 months to obtain a more accurate estimate of the program's ROI. 
6000

$-$

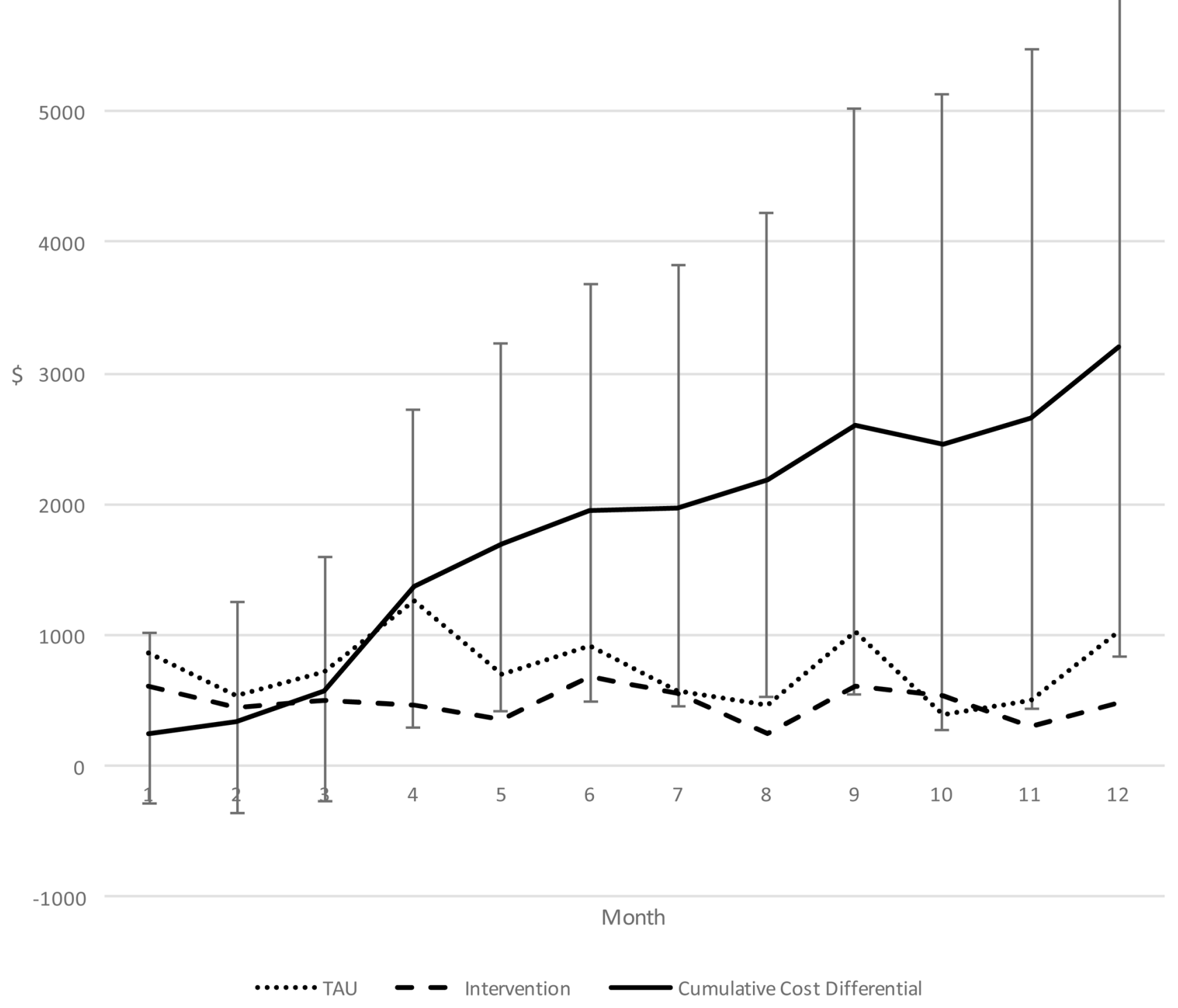

Figure 1.

Costs Over Time

JEmerg Med. Author manuscript; available in PMC 2018 August 01. 


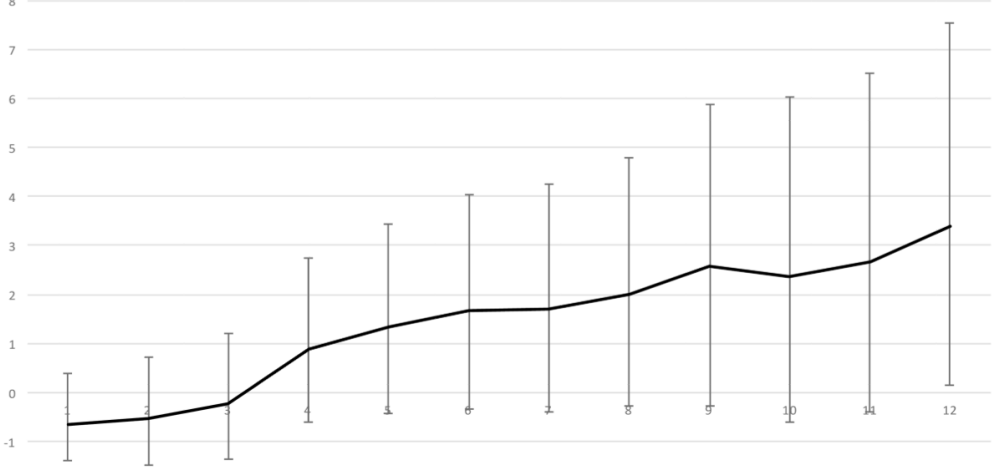

Mont

Figure 2.

Return on Investment (ROI) Over Time 


\section{Table 1}

\section{Descriptive Statistics}

\begin{tabular}{|c|c|c|}
\hline & Intervention $(\mathbf{n}=82)$ & TAU $(\mathbf{n}=\mathbf{8 1})$ \\
\hline Variable & Mean & Mean \\
\hline \multicolumn{3}{|l|}{ Demographics $(95 \% \mathrm{CI})$} \\
\hline Male & $28 \%(19 \%, 39 \%)$ & $32 \%(22 \%, 43 \%)$ \\
\hline Age (Median; IQR) & $39(34 ; 20)$ & $37(34 ; 19)$ \\
\hline White/Caucasian & $80 \%(70 \%, 88 \%)$ & $84 \%(74 \%, 91 \%)$ \\
\hline Black/African American & $4 \%(1 \%, 10 \%)$ & $4 \%(1 \%, 10 \%)$ \\
\hline Hispanic/Latino(a) & $5 \%(1 \%, 12 \%)$ & $6 \%(2 \%, 14 \%)$ \\
\hline Other race & $11 \%(5 \%, 20 \%)$ & $6 \%(2 \%, 14 \%)$ \\
\hline \multicolumn{3}{|l|}{ Primary insurance $^{\mathrm{a}}(95 \% \mathrm{CI})$} \\
\hline Private & $17 \%(10 \%, 27 \%)$ & $11 \%(5 \%, 20 \%)$ \\
\hline Medicare & $21 \%(13 \%, 31 \%)$ & $11 \%(5 \%, 20 \%)$ \\
\hline Medicaid & $49 \%(38 \%, 60 \%)$ & $60 \%(49 \%, 71 \%)$ \\
\hline Other insurance & $1 \%(.03 \%, 7 \%)$ & $4 \%(1 \%, 10 \%)$ \\
\hline Self/charity & $12 \%(6 \%, 21 \%)$ & $14 \%(7 \%, 23 \%)$ \\
\hline \multicolumn{3}{|c|}{12 months prior to enrollment (Median; IQR) } \\
\hline Cost & $\$ 16,570(9,968 ; 13,269)$ & $\$ 16,581(11,392 ; 14,511)$ \\
\hline Visits & $15(14 ; 6)$ & $15(14,8)$ \\
\hline
\end{tabular}

JEmerg Med. Author manuscript; available in PMC 2018 August 01. 
Table 2

Predicted Mean Costs and Return on Investment (ROI)

\begin{tabular}{ccccccc}
\hline Month & Intervention & TAU & Cumulative Cost Differential (SE) & p-value & ROI (SE) & p-value \\
\hline 1 & 612 & 867 & $-255(322)$ & 0.43 & $-0.65(0.44)$ & 0.14 \\
2 & 446 & 538 & $-346(396)$ & 0.38 & $-0.52(0.54)$ & 0.34 \\
3 & 493 & 716 & $-570(460)$ & 0.22 & $-0.22(0.63)$ & 0.73 \\
4 & 457 & 1,257 & $-1,370(626)$ & 0.03 & $0.88(0.86)$ & 0.31 \\
5 & 360 & 693 & $-1,702(719)$ & 0.02 & $1.34(0.99)$ & 0.18 \\
6 & 686 & 925 & $-1,942(836)$ & 0.02 & $1.66(1.15)$ & 0.15 \\
7 & 555 & 574 & $-1,961(889)$ & 0.03 & $1.69(1.22)$ & 0.17 \\
8 & 245 & 469 & $-2,185(946)$ & 0.02 & $2.00(1.30)$ & 0.13 \\
9 & 612 & 1,025 & $-2,599(1,148)$ & 0.02 & $2.56(1.57)$ & 0.11 \\
10 & 531 & 388 & $-2,456(1,196)$ & 0.04 & $2.37(1.64)$ & 0.15 \\
11 & 302 & 508 & $-2,663(1,240)$ & 0.03 & $2.65(1.70)$ & 0.12 \\
12 & 487 & 1,024 & $-3,200(1,345)$ & 0.02 & $3.39(1.85)$ & 0.07 \\
\hline
\end{tabular}

J Emerg Med. Author manuscript; available in PMC 2018 August 01. 